\title{
Iberoamerican Ophthalmologists IOL Selection for Use on Themselves: Survey Results
}

This article was published in the following Dove Press journal:

Clinical Ophthalmology

\author{
Daniel Scorsetti ${ }^{1,2}$ \\ Eduardo Viteri $\mathbb{1}^{3}$ \\ Eduardo Mayorga (iD ${ }^{4}$ \\ 'Scorsetti Institute, Buenos Aires, \\ Argentina; ${ }^{2}$ School of Medicine, \\ Universidad del Salvador, Buenos Aires, \\ Argentina; ${ }^{3}$ Humana Vision \\ Ophthalmological Center, Guayaquil, \\ Ecuador; ${ }^{4}$ Eye Department, Italian \\ Hospital of Buenos Aires, Buenos Aires, \\ Argentina
}

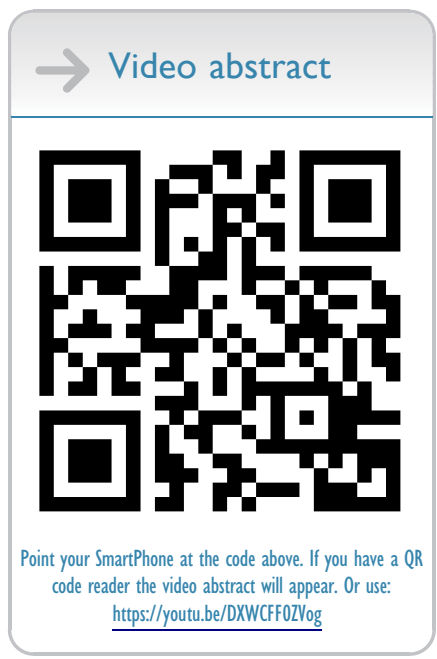

Correspondence: Daniel Scorsetti Instituto Scorsetti, Avenida Córdoba 20I I, Buenos Aires, II20, Argentina Tel +54 I I496400 I I

Email dscorsetti@gmail.com
Purpose: To determine the preferred type of intraocular lens (IOL) that ophthalmologists would choose for themselves in case of cataract surgery.

Design: Prospective convenience questionnaire study.

Materials and Methods: We developed an electronic survey with seven (7) questions, combining multiple and open options. The following categories were established: monofocal (MonoIOL) without monovision (MonoIOL-SM) and with monovision (MonoIOL-CM) and multifocal (MultiIOL) that could be either a bifocal (MultiIOL-B), trifocal (MultiIOL-T) or extended focus (MultiIOL-E). The link for the survey was sent to ophthalmologists from Latin America and Spain through different ways. The 1209 responses were analyzed statistically.

Results: We received 1209 responses from 14 countries. The average age was 47.977 years (SD 11.711 years). Gender distribution was 839 males (72.8\%) and 313 females $(27.2 \%)$. Overall preference was MonoIOL-SM 23.90\% (289), MonoIOL-CM 12.16\% (147), MultiIOL-B 4.63\% (56), MultiIOL-T 34.99\% (423), MultiIOL-E 15.22\% (110), and unsure $9.10 \%$ (110). Ophthalmologists that implant IOLs showed a greater preference for MultiIOL (64\%) than those who did not implant IOLs (32.3\%). Although all ophthalmologists preferred MultiIOL, anterior segment specialists chose them more frequently $(59.1 \%)$ than posterior segment specialists (41\%).

Conclusion: Ophthalmologists would prefer to receive a multifocal IOL implantation despite the lower frequency of multifocal IOL implantation observed in the general population. The frequency was greater among ophthalmologists who implant IOLs compared to those who do not implant them. It was also greater among those who identified themselves as anterior segment specialists compared to posterior segment specialists.

Keywords: ophthalmologists, IOL type, cataract surgery

\section{Introduction}

Cataract surgery is one of the most frequent procedures performed. It is estimated that 4.5 million surgeries were performed in Europe in 2016 according to Eurostat ${ }^{1}$ and about 3 million surgeries are performed each year in the United States. The technique of choice is the extraction of the lens through a small corneal or corneoscleral incision, preserving the capsular bag. Once the entire content of the lens is removed, an intraocular lens implant is placed inside the capsular bag.

Intraocular lens (IOL) implantation has the aim to restore the focus of the images on the retina, which is lost when the lens is removed. Since the use of intraocular lenses was first described in the middle of the last century, they have continuously evolved to deliver a better visual quality. Several strategies have also been used to 
achieve good distance and near vision, like using lenses with more than one focal point in both eyes, focusing one eye for near vision and the other one for distance vision, or a combination of both. ${ }^{2}$

So far, no IOL type is the first choice of all surgeons. Each of the strategies currently used has advantages and disadvantages. The surgeon decides which one to use based on different considerations like the patient's preferences, the surgeon's personal experience in terms of previous results as well as experience on multifocal IOL implantation, cost and patient's economic status and availability of certain lenses in the workplace. Due to these factors, it is difficult to determine a trend in IOL election.

Based on the above, it seemed to us that a relatively easy way of evaluating implantation trends would be to ask ophthalmologists which intraocular lens they would choose for implantation if they needed cataract surgery.

\section{Materials and Methods}

\section{Study Design}

Prospective, non-randomized online survey.

\section{Study Population}

Ophthalmologists belonging to the Ophthalmological Societies in Latin America and Spain Sociedad Argentina de Oftalmología (SAO), Consejo Argentino de Oftalmología (CAO), Sociedad Española de Oftalmología (SEO), Sociedad Colombiana de Oftalmología, Sociedad Venezolana de Oftalmología, Sociedad Dominicana de Oftalmología, Sociedad Ecuatoriana de Oftalmología, Sociedad Mexicana de Oftalmología, Sociedad Ecuatoriana de Catarata y Segmento Anterior (SESCA), Foro FacoElche, OftalmoLOGI (Facebook Group), PAAO Campus,
OftalmoCaribe, Newsletter Oftalmólogo Al Día, ESO Graduates (Instituto Barraquer de América) who agreed to collaborate in the study, as well as several discussion groups of electronic mail, Facebook and electronic messaging restricted to ophthalmologists residing in Latin America and Spain.

\section{Subject Solicitation}

The ophthalmologists received an invitation to participate in this study through the link to the survey sent to the email lists of the participating Societies, ophthalmology graduates, e-mail forums and groups of ophthalmologists in social networks (Facebook). We sent repeated invitations during the one-month period of data reception, from April 15 to May 15, 2019. We don't included an Ethics committee because the survey was anonymous, the identity of the ophthalmologists was preserved and there were no patients involved.

\section{Survey Tool}

The survey was conducted online, using the commercially available Survey Monkey ${ }^{\mathrm{TM}}$ application. The form was prepared in Spanish with sequential multiple-choice questions. Demographic information was limited to age, sex and country of residence (an English translation is available in Figure 1).

Regarding the classification of Intraocular Lenses (IOLs), we created two groups: Monofocal and Multifocal. The monofocal group (MonoIOL) comprised MonoIOL without monovision (MonoIOL-SM) and with monovision (MonoIOL-CM). The multifocal group (MultiIOL) was divided in bifocal (MultiIOL-B), trifocal (MultilOL-T) and extended focus (MultiIOL-E). The survey was not validated, so the questions were direct and to avoid bias. The survey did not mention IOL brands or models.

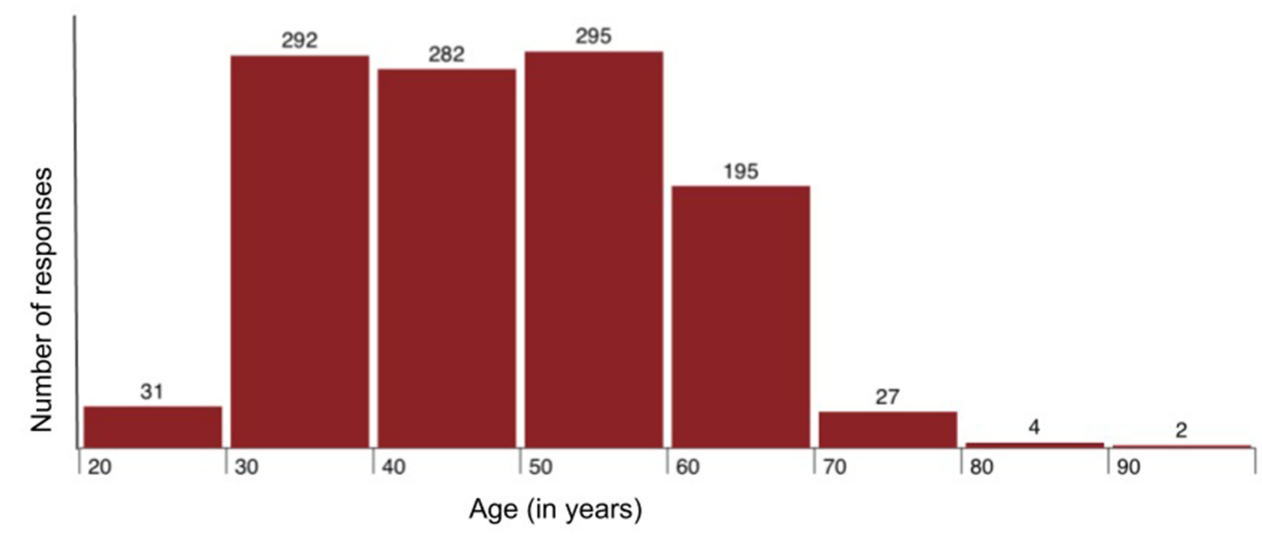

Figure I Intraocular lens survey for ophthalmologists. 


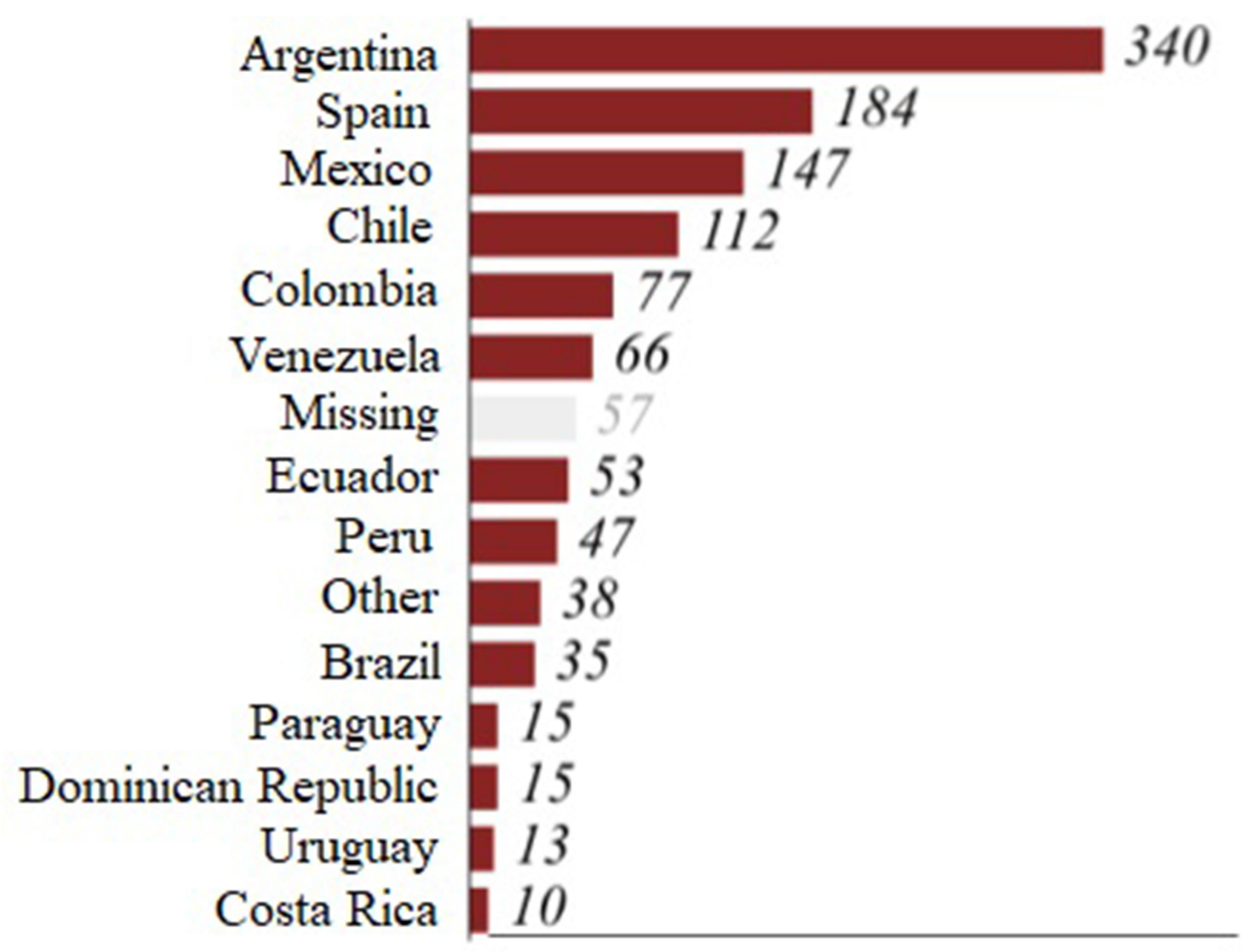

Number of responses

Figure 2 Number of responses by age group.

We tried to reach as many respondents as possible. Given that both direct (sending email to individuals) and indirect (dissemination through web pages, medical forums and WhatsApp groups) methods were used, it was not possible to determine the total number of ophthalmologists reached or the response rate. Duplicate responses from the same device were blocked.

\section{Data Analysis}

The 1209 answers received were collected in an electronic spreadsheet and analyzed with a commercial statistics program for the Apple operating system (Wizard ${ }^{\mathrm{TM}}$ ).

\section{Results}

\section{Population Description}

We received 1209 responses, of which 839 (72.8\%) were male and 313 (27.2\%) female, with $4.7 \%$ not answering this question. The average age was 47.977 years (SD 11.711 years) with a range from 30 to 70 years of age (Figure 2).

The countries that contributed with more responses were Argentina (29.5\%), Spain (16\%), Mexico (12.6\%) and Chile (9.7\%). Almost 5\% of respondents did not report their country of residence (Figure 3).
Regarding the type of medical practice, $74.7 \%$ of the respondents answered as subspecialty anterior segment, $12.8 \%$ posterior segment and $3.4 \%$ general ophthalmologists. The remaining $9.1 \%$ includes residents in training, as well as subspecialists in oculoplastic, pediatric ophthalmology, uveitis, etc. Of the respondent ophthalmologists, $70.9 \%$ implanted intraocular lenses and $29.1 \%$ did not.

\section{Intraocular Lens Implantation}

Overall, $35 \%$ of ophthalmologists would choose a MultiIOL-T if they needed surgery, followed by a MonoIOL, chosen by $23 \%$ of the respondents. The new extended focus lenses were chosen by $15.2 \%$ of the respondents. Monovision was preferred by $12.2 \%$ and $9.1 \%$ responded they were unsure about the type of lens they would select.

Consolidating the results, we observed that $60.32 \%$ of the ophthalmologists, excluding the 110 who were unsure, would choose a multifocal lens in one of its variants.

The youngest ophthalmologists chose MonoIOL-SM (median 43 years), and the median age of those who choose one of the MultiIOL or monovision was of around 


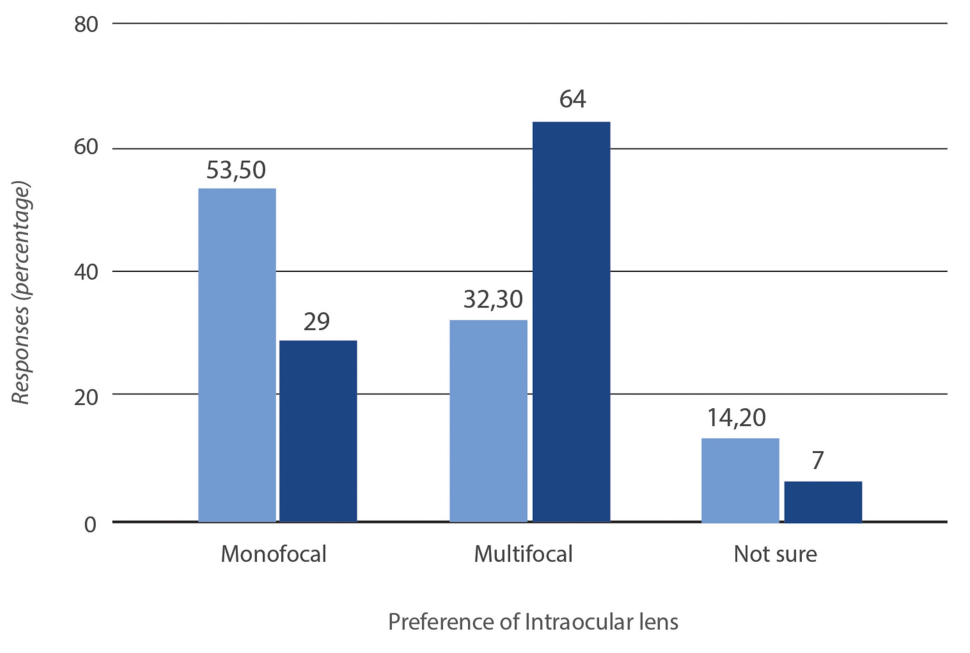

Do Not Implant

Implant

Figure 3 Number of responses by country of residence.

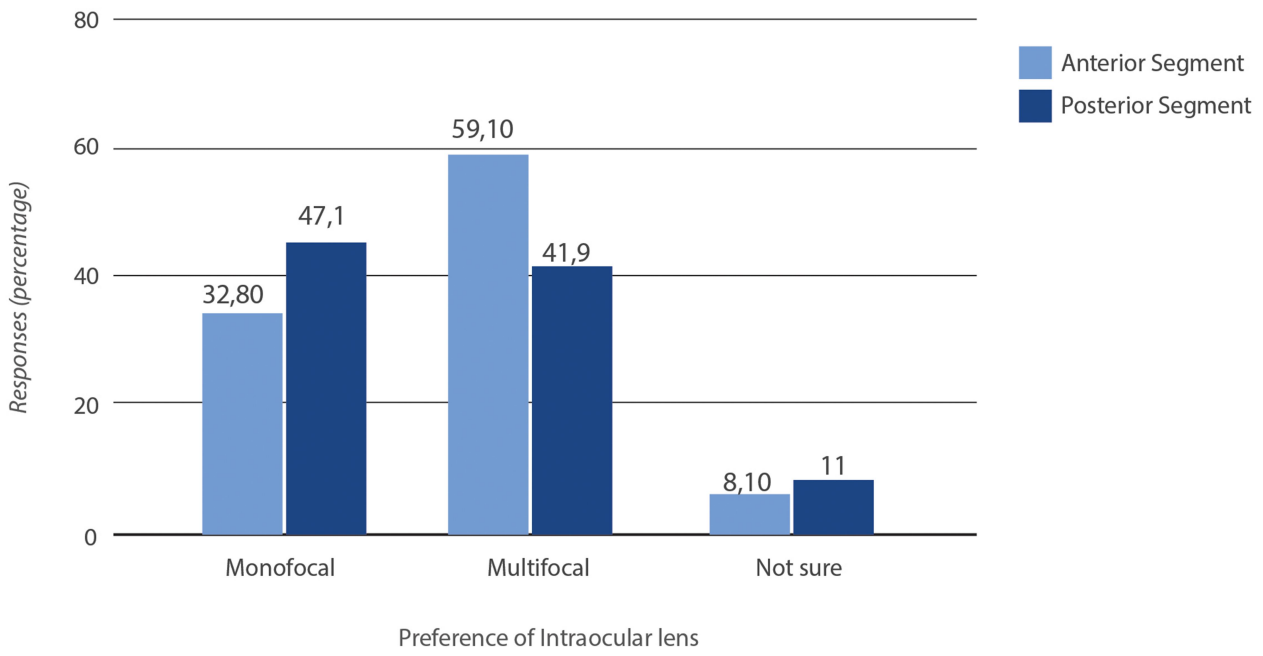

Figure 4 Lens type based on IOL implantation.

50 years (Kruskal-Wallis test, p-value $<0.001$ ). No differences were observed regarding sex.

As shown in Figure 4, when comparing the type of lens chosen by ophthalmologists that do or do not implant IOLs, we found that of the 352 ophthalmologists who do not implant lenses, the majority preferred a MonoIOL-SM (53.5\%), while those who implant lenses preferred MultiIOLs (64\%); this difference is statistically significant (Chi-square test, p-value $<0.001)$.

Figure 5 shows the results obtained when comparing anterior segment versus posterior segment specialists. A higher percentage of anterior segment surgeons would choose a MultiIOL (59.1\% versus $41 \%$ for posterior segment surgeons, Chi-square test; p-value $<0.05$ ).

\section{Discussion}

When there are several options for implants or medical devices, multiple factors influence the decision-making process. On one hand, there is the imbalance of information between the patient and the doctor, since the patient usually does not fully understand the implications of his or her decision and they are unable to dimension the different results if they had chosen another alternative. There are also potential conflicts of interest that may involve the provider (insurer or state institution) and the economic limitations related to multifocal IOLs. We understand that if an ophthalmologist would have to choose an IOL for himself, these factors are minimized. The result of this survey shows that, in case of needing cataract surgery, most ophthalmologists would choose a multifocal lens, regardless of age, sex, 
Intraocular Lens Survey for Ophthalmologists

1 -What is your subspecialty?

. Anterior Segment

. Posterior Segment

Other (specify)

2- Do you perform surgical procedures with intraocular lenses to treat presbyopia in patients with cataracts?

. Yes

. No

3- What lens would you choose for yourself if you had a cataract?

Single vision without monovision

. Single vision with monovision

Multifocal (bifocal)

Multifocal (trifocal)

Extended range

. I'm not sure

4- If you wish, you can make some clarification

5- How old are you?

20 to 30 years

30 to 40 years

.40 to 50 years

50 to 60 years

.60 to 70 years

.70 to 80 years

. More than 80 years

6- What is your gender?

. Female

Male

7- Country where you reside:

. Uruguay

. Chile

. Argentina

Figure 5 Continued. 


Peru
. Bolivia
. Brazil
. Paraguay
. Ecuador
. Colombia
Venezuela
. Mexico
. Dominican Republic
. Costa Rica
Guatemala
Honduras
. Nicaragua
. El Salvador
. Panama
. Puerto Rico
. Canada
. OsA

Figure 5 Type of lens selected by anterior versus posterior segment specialists.

type of practice or country of residence, even though there is still no unanimous consensus about this.

To the best of our knowledge, this is the first study conducted on the personal preference of intraocular lens type that Spanish-speaking ophthalmologists would select for themselves, classified by type of practice and previous experience implanting IOLs. Of the 1099 specialists answered the question on IOL preference, $663(60.32 \%)$ chose a multifocal IOL.

This is in sharp contrast with the figures of IOLs implanted in the general population; for example, the EUREQUO report of the European Society of Cataract and Refractive Surgery (ESCRS) on $2017,{ }^{3}$ stated that $1.7 \%$ of the IOLs implanted were multifocal (2066 of 124,523 cataract surgeries registered).

A recent article by Logothetis and Feder ${ }^{4}$ showed that of the 347 ophthalmologists that responded, $61.3 \%$ would choose a monofocal lens. This contrasts with our overall results that showed a higher percentage of ophthalmologists choosing multifocal IOLs for their own surgery. Nevertheless, this article reported that those surgeons more experienced in multifocal implantation are two times more likely to select a presbyopiacorrecting IOL, a result that agrees with our findings, that indicate that a surgeon's past experience may influence their choice of IOL for their own cataract surgery. However, we cannot exclude the influence of trying to avoid "cognitive dissonance", that is, that anterior segment surgeons who implant multifocal IOLs are unconsciously inclined to the option they advise their patients. The "overconfidence" bias and using a heuristic approach may also have an influence on the decision.

Both our study and that by Logothetis and Feder were not designed to compare personal IOL selection versus IOL selection for patients, making difficult to draw conclusions. However, there is published evidence that shows 
that the advice given by physicians to their patients is different from the choices they make for themselves in similar situations. An extreme example is a recent publication that compares the intensity of end-of-life medical care among doctors, lawyers and the general population. Since physicians have first-hand experience with the burdens and the futility of end-of-life care, they are less likely to undergo surgery or accept admission to the ICU during the last six months of life, leading to fewer deaths in the hospital. ${ }^{5}$

We also have a clear example in a study about the prevalence of laser visual correction (LVC) in the USA among ophthalmologists who perform refractive surgery. ${ }^{6}$ In this online survey, $62.6 \%$ of the surgeons who were candidates for LVC had it performed on their own eyes and more than $90 \%$ of all respondents recommended it for their immediate family. This percentage is four times higher than actual LVC figures in the general population in the USA at that moment, of only $13.1 \%{ }^{7}$ Likewise, refractive surgeons reported that $63.4 \%$ of their immediate relatives had undergone LVC.

The enormous difference between the frequency of multifocal IOL implantation in the general population $(2-5 \%)$ and the preference for this type of lens among the ophthalmologists surveyed $(60.32 \%)$ is evident. This finding is consistent with the previously mentioned report on refractive surgery among ophthalmologists and may be explained by several factors like a better understanding of the available options, deep knowledge about results, greater access to IOLs with advanced technology, a higher economic capacity and/or facilities given by insurers and suppliers. Regarding costs, if a properly powered study shows that the reason of not implanting more multifocal IOLs in patients is due to the cost, then one could explore ways to democratize the access of a greater number of people to multifocal IOLs.

The result of the survey is conclusive regarding the IOL preference between ophthalmologists and the difference between the decisions that ophthalmologists would make for themselves and the real figures on the type of IOL implanted. However, our study has obvious limitations. First, we were not able to establish the response rate, since there was no way of monitoring how many ophthalmologists received the survey but decided not to answer it. Another limitation is that we did not obtain a homogeneous response from all Latin American countries, so the results may not be representative of the region. In addition, since the survey was virtual, it did not include ophthalmologists with limited access to technology. Finally, the answers were not audited, and we were not able to independently verify the information provided by the participants.

Nevertheless, it is clear that this study opens new perspectives on the difference between the IOLs generally implanted and those that ophthalmologists consider the best option for themselves. Based on our results, we suggest conducting new studies related to different aspects of the ophthalmological practice that allow obtaining higherlevel evidence while minimizing possible biases such as overconfidence, confirmation and other heuristics, so frequent among doctors and surgeons.

It would be ideal to design a study that identifies ophthalmologists who have undergone cataract surgery to establish which type of IOL was actually implanted as well as the degree of satisfaction with visual results. The same methodology would be useful for different treatments in this and other specialties.

\section{Conclusions}

Most Spanish-speaking ophthalmologists would select a multifocal IOL for themselves. This choice is more frequent than that observed in the general population for multifocal IOL implantation. The preference for multifocal IOLs is significantly higher among ophthalmologists with previous experience in IOL implantation and anterior segment specialists, compared to posterior segment specialists and ophthalmologists who do not perform cataract surgery and IOL implantation.

\section{Abbreviations}

MonoIOL, Monofocal; MonoIOL-SM, Monofocal without monovision; MonoIOL-CM, Monofocal with monovision; MultiIOL, Multifocal; MultiIOL-B, Bifocal; MultiIOL-T, Trifocal; MultiIOL-E, Extended focus; IOL, Intraocular lens; LVC, Laser visual correction.

\section{Acknowledgments}

For disclosing the survey: Consejo Argentino de Oftalmología (CAO), Sociedad Argentina de Oftalmología (SAO), Sociedad Española de Oftalmología (SEO), Foro Facoelche, Sociedad Colombiana de Oftalmología, Sociedad Venezolana de Oftalmología, Sociedad Dominicana de Oftalmología, Sociedad Ecuatoriana de Oftalmología, Sociedad Ecuatoriana de Catarata y Segmento Anterior (SECSA), Sociedad Mexicana de Oftalmología, Newsletter Oftalmólogo Al 
Día, OftalmoLOGI (Facebook Group), PAAO Campus, OftalmoCaribe, andESO graduates (Instituto Barraquer de América).

\section{Funding}

The authors state that they received no funding for this work.

\section{Disclosure}

The authors report no conflicts of interest in this work.

\section{References}

1. European Commission; eurostat. Cataract surgery: how countries compare. Available from: https://ec.europa.eu/eurostat/web/productseurostat-news/-/DDN-20190108-1. Accessed February 27, 2021.
2. Davis G. Evolution of cataract surgery. Mo Med. 2016;113(1):58-62.

3. EUREQUO Steering Committee. ECRS; EUROWUO; Annual Report 2017. Available from: http://www.eurequo.org/wp-content /uploads/2018/11/EUREQUO_Annual_Report2017.pdf. Accessed February 27, 2021.

4. Logothetis HD, Feder RS. Which intraocular lens would ophthalmologists choose for themselves? Eye. 2019;33(10):1635-1641. doi:10.1038/s41433-019-0460-9

5. Weissman JS, Cooper Z, Hyder JA, et al. End-of-life care intensity for physicians, lawyers, and the general population. JAMA. 2016;315 (3):303-305. doi:10.1001/jama.2015.17408

6. Kezirian GM, Parkhurst GD, Brinton JP, Norden RA. Prevalence of laser vision correction in ophthalmologists who perform refractive surgery. $J$ Cataract Refract Surg. 2015;41(9):1826-1832. doi:10.1016/j.jcrs.2015.10.027

7. Harmon D. 2014 Report on the Refractive Surgery Market. Market Scope; 2014.

\section{Publish your work in this journal}

Clinical Ophthalmology is an international, peer-reviewed journal covering all subspecialties within ophthalmology. Key topics include: Optometry; Visual science; Pharmacology and drug therapy in eye diseases; Basic Sciences; Primary and Secondary eye care; Patient Safety and Quality of Care Improvements. This journal is indexed on PubMed
Central and CAS, and is the official journal of The Society of Clinical Ophthalmology (SCO). The manuscript management system is completely online and includes a very quick and fair peer-review system, which is all easy to use. Visit http://www.dovepress.com/ testimonials.php to read real quotes from published authors. 